\title{
Suksesi kepemimpinan pentakostal di era disruptif
}

\author{
Mikha Agus Widiyanto ${ }^{1}$, Yohanes Parapat ${ }^{2}$ \\ ${ }^{1}$ Sekolah Tinggi Teologi Tenggarong, Kalimantan Timur \\ ${ }^{2}$ Sekolah Tinggi Teologi Ekumene, Jakarta \\ 1mikha.agus08@gmail.com, 2yohanes.asp@gmail.com
}

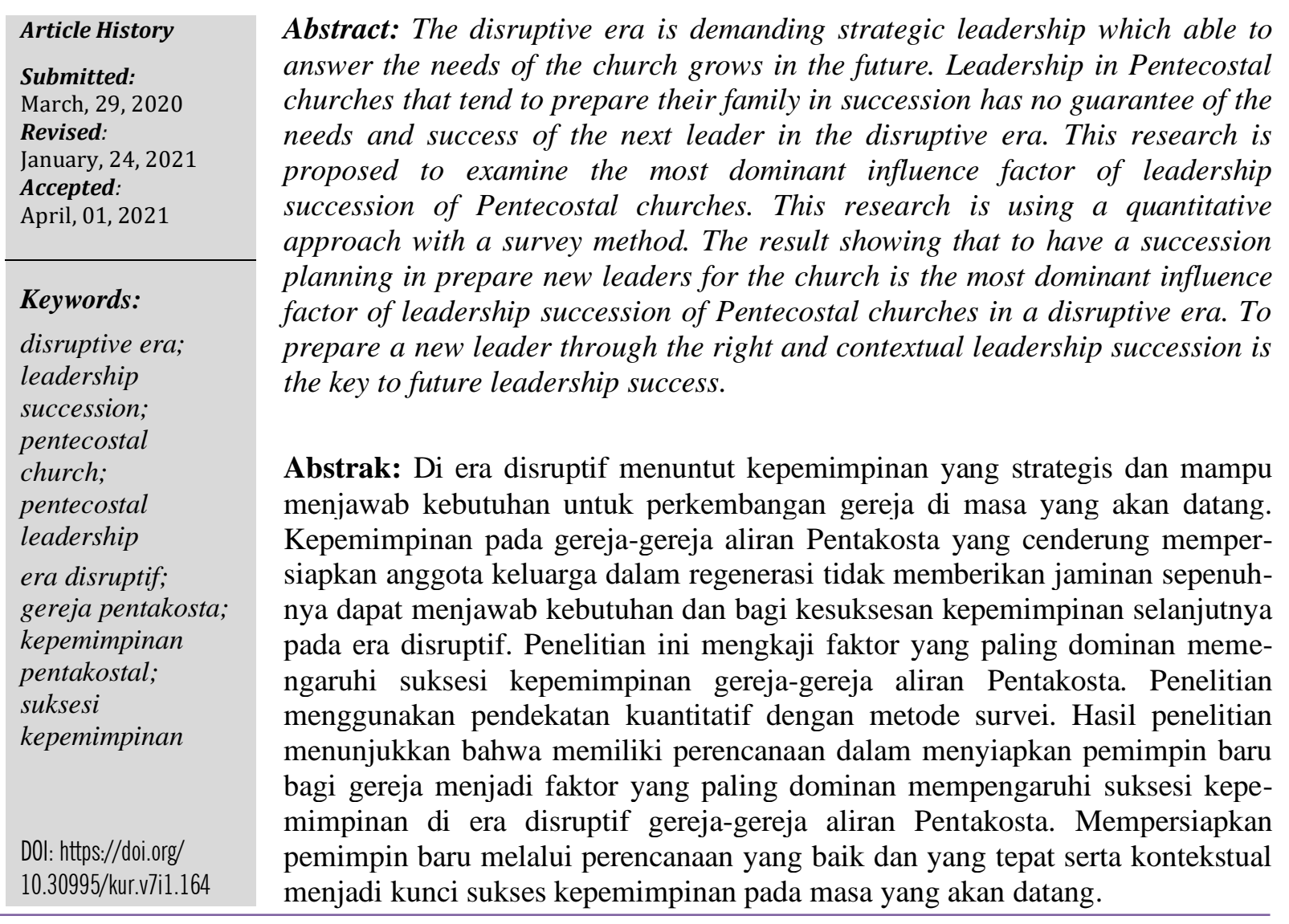

\section{Pendahuluan}

Pemimpin gereja memegang peranan penting yang dalam tugas kepemimpinannya yang menentukan maju dan mundurnya organisasi gereja yang dipimpinnya. Keberhasilan dalam suatu organisasi yang ditandai dengan ketercapaiannya atau realisasi dari tergantung pada kepemimpinan. ${ }^{1}$ Wijaya mengutip Frunza bahwa adanya gejala-gejala krisis kepemimpinan yang dialami organisasi secara khusus dalam konteks gereja. Adanya gereja dalam sistim suksesi kepemimpinan belum berjalan dengan semestinya. Bagi gereja tertentu masih ketergantungan terhadap pemimpin lama yang sebenarnya masa baktinya sudah selesai, namun tetap mempertahankan, sehingga terjadi nepotisme dan fevoritisme yang berdampak

${ }^{1}$ Jacob M. Selesho, "The Role of Leadership in Organisational Regeneration: Incident of School Improvement," Mediterranean Journal of Social Sciences 5, no. 7 (2014): 317-323. 
pada ketidakpuasan pihak-pihak tertentu yang menghendaki pada sistim yang fair dan transformatif. ${ }^{2}$

Fenomena pada gereja aliran Pentakosta, kecenderungannya mengalihkan kepemimpinan pada generasi selanjutkan dari kalangan keluarga. Pemikirannya didasarkan pada faktor pemimpin sebagai perintis gereja, sehingga menghendaki suksesi kepemimpinannya pada generasi selanjutnya dari kalangan keluarganya. Suksesi kepemimpinan sangat menentukan kemajuan dan perkembangan gereja di masa yang akan datang. Namun suksesi kepemimpinan yang berorientasi pada generasi keluarga tidak menjamin akan keberhasilan pada kepemimpinan selanjutnya. Artinya suksesi kepemimpinan tersebut harus juga memperhatikan kualitas Sumber Daya Manusianya. Wanggi, Panggabean dan Puspa menyatakan bahwa upaya untuk mencapai suksesi kepemimpinan yang tepat dan efisien, maka perlu dilakukan pengembangan Sumber Daya Manusia yang terprogram dengan baik. ${ }^{3}$ Bisa saja, gereja Aliran Pentakosta mengalihkan suksesi kepemimpinannya dari keluarga, namun perlu persiapan dan pelatihan melalui perencanaan yang terprogram dalam pengembangan kualitas Sumber Daya Manusianya. Kualitas sumber daya manusia terkait dengan kompetensi dan penguasaan terhadap perkembangan zaman. Menurut Objantoro bahwa secara khusus kompetensi dalam menghadapi perkembangan teknologi secara pesat di era disruptif sekarang ini. ${ }^{4}$ Di era disruptif teknologi di mana umat sudah memasuki dunia digital, namun sebagian pemimpin gereja belum menunjukkan kesiapan dalam menghadapinya. ${ }^{5}$ Pemimpin gereja yang akan datang secara khusus dalam program suksesi, sudah semestinya mempersiapkan generasi yang memiliki kemampuan dalam penguasaan teknologi.

Moores and Barrett yang dikutip kamener dan Putri bahwa suksesi merupakan peralihan kepemilikan kepada keluarga kepada suksesor dari pemilik sebelumnya. ${ }^{6}$ Sedangkan Salleh dan Rahman menyatakan bahwa suksesi berkenaan dengan pergeseran kepemilikan. ${ }^{7}$ Dalam kontek kepemimpinan gereja, maka suksesi berkenaan dengan pergantian pemimpin gereja dari pemimpin yang lama kepada pemimpin berikutnya. Suksesi yang sering terjadi dalam praktek organisasi dalam hal ini gereja aliran Pentakosta, yaitu dari orangtua kepada anggota keluarga. Remiasa dan Wijaya menyatakan bahwa proses suksesi yang tepat akan membuat organisasi akan tetap eksis meskipun pendiri atau pemimpin yang lama tidak lagi terlibat secara aktif dalam mengelolanya. Suksesi kepemimpinan membutuhkan proses yang cukup

${ }^{2}$ Yahya Wijaya, “Kepemimpinan Yesus Sebagai Acuan Bagi Kepemimpinan Gereja Masa Kini,” Jurnal Jaffray 16, no. 2 (2018): 129, http://doi.org/10.25278/jj71.v16i2.287.

${ }^{3}$ Amelia Wanggi, Mutiara Panggabean, and Tiara Puspa, "Pengaruh Succession Planning,

Transformational Leadership, Training Satisfaction Terhadap Turnover Intention Karyawan Pada Sektor Publik Kementerian Agama Jakarta Pusat," Esensi: Jurnal Bisnis dan Manajemen 9, no. 1 (2019): 79-90, http://doi.org/10.15408/ess.v9i1.12491.

${ }^{4}$ Enggar Objantoro, "Religious Pluralisme and Christian Responses," Evangelikal: Jurnal Teologi Injili dan Pembinaan Warga Gereja 2, no. 1 (2018): 1-9, https://doi.org/10.46445/ejti.v2i1.94.

${ }^{5}$ Daniel Ronda, “Kepemimpinan Kristen Di Era Disrupsi Teknologi," Evangelikal: Jurnal Teologi Injili dan Pembinaan Warga Jemaat 3, no. 1 (2019): 1, http://doi.org/10.46445/ejti.v3i1.125.

${ }^{6}$ Dahliana Kamener and Daniati Putri, "Analisis Keberhasilan Suksesi Perusahaan Keluarga Di Kota Padang," Industrial Research Workshop and National Seminar Politeknik (2017): 20-26.

${ }^{7}$ Lailawati Mohd. Salleh and Muhammad Fadhi Abdul Rahman, "A Comparative Study of Leadership Succession Models.," Science International 29, no. 4 (2017): 791-796, https://lib.pepperdine.edu/login?url. 
panjang yang menentukan keberhasilan organisasi. Pemilihan suksesor yang tepat akan membuat organisasi terus bertahan dan bahkan berkembang dengan baik. ${ }^{8}$

Marpa, Colgan dan Hnatek yang diputip Atmaja bahwa terdapat dua faktor yang menjadi penghambat suksesi kepemimpinan, yaitu faktor dari calon suksesor sendiri dan hubungan keluarga. Faktor suksesor sendiri terkait dengan motivasinya untuk melanjutkan kepemimpinan orang tua dan faktor keluarga terkait orangtua yang tidak ingin regenerasi, ingin memimpin sampai seumur hidupnya dan sikap kurang adil terhadap anggota keluarga yang akan menerima suksesi kepemimpinannya. ${ }^{9}$ Perlu disadari bahwa tidak semua anggota keluarga memiliki dorongan atau motivasi untuk suksesi kepemimpinan dari orang tua. Konteks Saul sebagai Raja bagi bangsa Israel tidak menjadi jaminan, anaknya Yonathan untuk meneruskan kepemimpinannya bagi bangsa Israel. Justru Allah memilih Daud untuk melanjutkan kepemimpinan bagi bangsa Israel (1Sam. 16:13).

Konteks Imam Eli, di mana anak-anaknya sebagai keturunan imam yang semestinya meneruskan suksesi kepemimpinan orangtuanya. Namun, Hofni dan Pinehas semestinya melanjutkan kepemimpinan Imam Eli. Tetapi kualitas diri yang menunjuk pada moralitas yang tidak sesuai dengan standar Tuhan, menjadikan Hofni dan Pinehas sebagai orang-orang dursila (1Sam. 2:11-36). Tuhan justru mempercayakan kepemimpinan bagi bangsa Israel kepada Samuel sebagai seorang hakim (1Sam. 7:15-17). Meskipun demikian, suksesi kepemimpinan juga terlihat dalam diri daud ketika tongkat estafet kepemimpinan diteruskan kepada Salomo. Faktor penghambat suksesi kepemimpinan dari aspek keluara juga terjadi dalam masa kepemimpinan Daud sebagai raja bagi bangsa Israel. Absalom yang merencanakan kejahatan dalam menggulingkan kepemimpinan Daud (2Sam. 15:1-12). Suksesi yang dipaksanakan oleh Absalom, membuat Daud melarikan diri meninggalkan Yerusalem (2Sam. 15:13-37).

Era disruptif diartikan sebagai masa di mana bermunculan inovasi-inovasi yang tidak terlihat, yang tidak disadari oleh organisasi, namun keberadaannya mengganggu tatanan aktivitas dari sistem yang telah lama berlaku, dan yang secara perlahan mematikan sistim yang lama tersebut. Era disruptif tidak hanya berkenaan dengan perkembangan dan inovasi pada teknologi informasi dan komunikasi yang terjadi pada saat ini, namun mengacu pada perubahan-perubahan yang akan datang. ${ }^{10}$ Sedangkan Bakar, Panggabean, dan menyatakan bahwa disruptif sebagai gambaran akan kondisi pergesaran sistem lama dengan cara-cara baru yang lebih inovatif dan kreatif. ${ }^{11}$ Perubahan tersebut yang mengubah sistim, tatanan dan aktivitas dari yang lama ke sistim dan tanatanan serta aktivitas yang baru sesuai dengan

\footnotetext{
${ }^{8}$ Marcus Remiasa and Shelvy Anggraini Wijaya, "Analisis Proses Suksesi Perusahaan Keluarga Studi Pada Pt Puterasean,” Kinerja 18, no. 2 (2014): 141-156.

${ }^{9}$ Hanung Eka Atmaja, "Suksesi Kepemimpinan Perusahaan Di Indonesia," Jurnal Rekomen (Riset Ekonomi Manajemen) 1, no. 2 (2018): 45-56.

${ }^{10}$ Rizki Widyawulandari, Sarwanto Sarwanto, and Mintasihu Indriayu, "The Use of Interactive Multimedia in Learning Based on Disruption Era At Elementary School," Social, Humanities, and Educational Studies (SHEs): Conference Series 1, no. 1 (2018): 697-704.

${ }^{11}$ Resekiani Mas Bakar, Benny Enrico Leonard Panggabean, and Eva Meizarra Puspita Dewi, "Tantangan Pendidikan Di Era Disruptif: Ujian Online Berbasis Smartphone Dengan Pengembangan Aplikasi XSIA," Jurnal Psikologi Talenta 4, no. 1 (2018): 30-39, http://ejournal.uinsuska.ac.id/index.php/psikologi/article/view/165.
} 
konteks perubahan dan perkembangannya. Perubahan ini juga terjadi pada aspek kepemimpinan.

Di era disruptif menuntut strategi kepemimpinan yang kontekstual dan mampu menjawab kebutuhan secara khusus bagi kelompok generasi milenial. ${ }^{12}$ Era Disruptif menuntut pemimpin yang kreatif dan memahami serta memiliki penguasaan terhadap teknologi. Pemimpin pada era disruptif harus mampu mengantisipasi dan mengikuti perkembangannya, secara khusus perlu suksesi kepemimpinan yang tepat agar mampu menjawab perkembangan dan kebutuhan seiring dengan perkembangan teknologi informasi dan komunikasi (ITC). Dalam perkembangan sekarang ini, secara khusus di tengah pandemi Covid-19, pelayanan gereja bergeser pada online, virtual atau live streaming yang semuanya itu memerlukan penguasaan teknologi. Artinya dalam era disrupif sekarang ini, dituntut seorang pemimpin yang memahami dan memiliki penguasaan dalam penggunaan berbagai aplikasi hasil dari pengembangan teknologi agar pelayanan menjadi efektif. Rapat-rapat koordinasi, rapat kerja, konferensi gereja dan sejenisnya dalam masa sekarang yang tidak memungkinkan mengumpulkan majelis, pekerja atau pelayanan gereja berkumpul secara tatap muka di gereja karena pandemik Covid-19. Teknologi informasi dan komunikasi menjadi solusi dengan ketersediaan berbagai aplikasi yang harus dipahami dan dikuasai penggunaannya oleh pemimpin gereja.

Sandel yang dikutip Wasono dan Furinto dalam penelitiannya bahwa dalam era disruptif diperlukan pemimpin yang memiliki kemampuan dan kapasitas yang dapat mengoptimalkan teknologi dan kemampuan digital. Dibutuhkan pemimpin yang memiliki karakteristik kreatif, menginspirasi, kredibel, pengetahuan yang lebih luas, pemimpin yang kolaboratif dan interaktif, serta mempercayai orang yang dipimpin. ${ }^{13}$ Menurut Chou bahwa dari hasil-hasil penelitian menunjukkan bagi generasi di era disruptif secara khusus pada kelompok generasi milenial lebih menyukai model kepemimpinan yang baik dalam mengatur tim, memotivasi dengan tugas-tugas yang signifikan, lebih menyukai komunikasi yang intens dan terbuka serta memahami teknologi komunikasi. ${ }^{14}$

Keberadaan pemimpin pada era sekarang, secara khusus pemimpin pada generasi Babby Boomer dan generasi X akan mengalami kendala keika memimpin generasi milenial yang menuntut serba digital. Pergeseran generasi membawa peluang dan tantangan bagi gereja. Menurut Howe dan Strauss yang dikutip Pyoria, et.al, bahwa generasi X didefinisikan bagi orang-orang yang lahir pada akhir 1960-an dan 1970-an, dan Milenium sebagai yang lahir kemudian, sekitar lahir pada tahun 1982 sampai 2004 (Smola \& Sutton, 2002). ${ }^{15}$ Putriastuti dan Stasi menyatakan bahwa generasi millenial memiliki nilai, harapan, dan sikap

${ }^{12}$ Bernadeta Cahya Kumala Putriastuti and Alessandro Stasi, "How to Lead the Millennials: A Review of 5 Major Leadership Theory Groups," Journal of Leadership In Organizations 1, no. 2 (2019): 96-111, https://doi.org/10.22146/jlo.46562.

${ }^{13}$ Leonardus W. Wasono and Asnan Furinto, "The Effect of Digital Leadership and Innovation Management for Incumbent Telecommunication Company in the Digital Disruptive Era," International Journal of Engineering and Technology(UAE) 7, no. 2 (2018): 125-130.

${ }^{14}$ Shih Yung Chou, "Millennials in the Workplace: A Conceptual Analysis of Millennials' Leadership and Followership Styles," International Journal of Human Resource Studies 2, no. 2 (2012): 71-83, http://doi.org/10.5296/ijhrs.v2i2.1568.

${ }^{15}$ Pasi Pyöriä et al., "The Millennial Generation: A New Breed of Labour?," SAGE Open 7, no. 1 (2017): 1-14, http://doi.org/10.1177/2158244017697158. 
yang berbeda dari generasi sebelumnya. ${ }^{16}$ Gereja harus mampu mengembangkan kepemimpinan yang tepat dengan mengubah strategi, secara khusus dalam pengkaderan dan mempersiapkan pemimpin dari generasi milenial. Penerapan kepemimpinan pada generasi berbeda menuntut pendekatan dan strategi yang berbeda. Suksesi kepemimpinan pada era sekarang terletak pada kreativitas dan pendekatan yang relevan bagi pemimpin dalam mempersiapkan atau regenerasi.

Menjawab tantangan dan dalam upaya memenuhi kebutuhan sesuai dengan era perkembangannya, maka regenerasi sangatlah penting untuk menjadi perhatian bagi pemimpin gereja. Shergold menyatakan bahwa regenerasi perlu dilakukan dalam merespons perubahan yang berkelanjutan, guna mewujudkan organisasi yang efektif dan efisien dalam memberikan pelayanan dengan meningkatkan inovasi-inovasi untuk mewujudkan kinerja yang baik. ${ }^{17}$ Melihat perkembangan secara khusus era disruptif, maka dalam suksesi kepemimpinan harus benar-benar dapat melakukan regenerasi yang dapat menjwab tantangan tersebut. Regenerasi tidak hanya berorientasi pada anggota keluarga dalam kepemimpinan gereja, namun benar-benar dipersipakan dalam berbagai aspek, sehingga ketika dirinya menerima tongkat estafet dapat mengembangkan gereja yang dipercayakan kepadanya. Era disruptif membutuhkan pemimpin yang memiliki perencanaan strategis dan berfungsi. Kemampuan pemimpin menentukan kualitas dan efektivitas program strategis. Pemimpin yang efektif memahami bagaimana memobilisasi perencanaan strategis dalam mengatasi masalah yang menantang dan menghadapi masalah dengan sukses. ${ }^{18}$ Pemimpin yang efektif dirinya dapat memiliki perencanaan strategis dalam suksesi kepemimpinannya. Pemberdayaan dan pengembangan pemimpin di masa yang akan datang menjadi program yang dirancang secara strategis dan berkesinambungan demi kemajuan gereja yang dipimpinnya kelak.

Menurut Salleh dan Rahman, bahwa proses suksesi dimulai dengan analisis strategi organisasi yang didasarkan pada kemajuan dan pencapaian visi organisasi. Suksesi kepemimpinan tidak hanya melihat pada aspek kemampuan suksesor, melainkan memilih pemimpin yang cocok atau sesuai berdasarkan kebutuhan organisasi. Kemudian diikuti oleh proses pengembangan melihat kepribadian yang dimiliki dan soft skill terkait bidang tugas, serta kemampuan dalam memimpin orang lain. Langkah selanjutnya melakukan penilaian dan evaluasi suksesor, dan akhirnya membuat perencanaan yang efektivitas dalam proses selanjutnya. ${ }^{19}$ Dalam suksesi kepemimpinan tidak hanya menekankan pada aspek kemampuan saja, melainkan kesesuaian dengan kebutuhan organisasi. Dalam pengertian perlu untuk memberikan penilaian terhadap suksesor atas kesesuaian dirinya dalam mengembangkan dan mewujudkan tujuan organisasi. Kepribadian yang baik, secara khusus dalam konteks organisasi gereja, yaitu kepribadian yang mencerminkan Kristus menjadi kriteria yang penting dalam menentukan keberhasilan suksesi kepemimpinan.

97

${ }^{16}$ Putriastuti and Stasi, "How to Lead the Millennials: A Review of 5 Major Leadership Theory Groups.",

${ }^{17}$ Peter Shergold, "Regeneration: New Structures, New Leaders, New Traditions," Australian Journal of Public Administration 64, no. 2 (2005): 3-6, http://doi.org/10.1111/j.1467-8500.2005.00428.x.

${ }^{18}$ Gregoruis Kukuh Nugroho, "Educational Leadership In Disruptive Era: A Faith Challenge Facing Indonesia," JPAK: Jurnal Pendidikan Agama Khatolik 19, no. 2 (2019): 91-100, https://doi.org/10.34150/jpak.v19i2.243.

${ }^{19}$ Salleh and Rahman, "A Comparative Study of Leadership Succession Models.”. 
Untuk menjadi seorang pemimpin di era disruptif, harus memiliki karakter, yang meliputi: Memiliki kerendahhati, yang tetap berorientasi pada hasil kerja yang optimal, dapat menyampaikan dan menjelaskan visi serta sasaran yang akan dicapai; Credible activist, mampu bekerja dengan sungguh-sungguh pada bidangnya dan berorientasi pada kontribusi yang optimal dan efisiensi; Fokus pada pembelajaran tim untuk menjadi sumber daya manusia yang berkualitas atau unggul; Memiliki penguasaan dan mampu memanfaatkan sistem manajemen dalam memajukan organisasinya. ${ }^{20}$ Sanjaya, yang dikutip Siahaya mengatakan, bahwa pemimpin yang berkarakter merupakan pemimpin yang mempunyai integritas. ${ }^{21}$ Sedangkan Lim menyatakan bahwa keberhasilan pemimpin bukan terletak pada pemahamannya tentang konsep kepemimpinan, kapabilitas kepemimpinan, karunia dan kharismanya, melainkan pada spiritualitasnya. ${ }^{22}$ Spiritualitas seseorang tidak hanya tercermin dalam aktivitas religiusnya melalui ibadah, melainkan juga tercermin dalam karakter yang ditampilkan ketika berinteraksi dengan orang lain. Karakter Kristus yang menjadi ukuran dari kualitas pemimpin. Pemimpin bagi gereja dituntut untuk memiliki karakter Kristus dalam kehidupannya (Rm. 8:29; 2Kor. 3:18; Ef. 3:10).

Suksesi kepemimpinan dari Musa kepada Yosua menunjukkan keberhasilan (Bil. 27:1223). Suksesi kepemimpinan yang dilakukan Musa bukan mendadak dan didasarkan pada keluarga. Musa mempersipakannya dengan baik. Ketika Musa memilih 12 orang pengintai yang salah satunya Yosua (Bil. 13:1-33). Tentunya ini bagian dari upaya Musa dalam mempersiapkan Yosua dan memberikan kepercayaan wujud dari pendelegasian tugasnya. Yosua memenuhi syarat sebagai pemimpin yang berkarater baik dan berintegritas. Yosua mampu melihat sisi positif dari apa yang dilihatnya ketika mengintai tanah Kanaan. Kualitas sebagai pemimpin telah ditampilkan Yosua ketika mampu memberikan informasi positif dalam memberikan dorongan dan semangat bangsa Israel menghadapi penduduk Kanaan. Optimisme yang ditunjukkan Yosua menunjukkan dirinya memenuhi kriteria sebagai seorang pemimpin di masa mendatang bagi bangsa Israel (Bil. 14:7-9). Dalam suksesi kepemimpinan bagi bangsa Israel, Musa menunjukkan kerendahan hati dan ketaatannya kepada Tuhan. Musa Bersama Tuhan Sang Pemimpin Yang Agung, mempersiapkan Yosua untuk memimpin umat Israel memasuki Tanah Perjanjian. ${ }^{23}$

Permasalahan dalam penelitian ini dirumuskan sebagai berikut: Faktor apakah yang paling dominan menentukan suksesi kepemimpinan gereja-gereja aliran Pentakosta di era disruptif? Adapun tujuan penelitian ini untuk menguji dan membuktikan faktor yang paling dominan mempengaruhi suksesi kepemimpinan gereja-gereja aliran Pentakosta.

\footnotetext{
20 “Trik Menjadi Pemimpin Di Era Disruptif,” n.d., https://ofiskita.com/articles/detail/trik-menjadipemimpin-di-era-disruptif (07 Desember 2019).

${ }^{21}$ Johannis Siahaya, "Kepmimpinan Kristen," Teruna Bhakti 1, no. 1 (2018): 1-16, http://ejournal.stakterunabhakti.ac.id/index.php/teruna/issue/archive.

${ }^{22}$ Alex Lim, "Integritas Spiritual Dan Kapabilitas Kepemimpinan Gereja Tionghoa," Veritas 11, no. 2 (2010): 207-229.

${ }^{23}$ Moury Setiawan Hidayat, "Studi Narasi Suksesi Kepemimpinan Musa Oleh Yosua, Dan Implikasinya Bagi Suksesi Kepemimpinan Rohani.” (Sekolah Tinggi Teologi SAAT, 2015), ii. http://repository.seabs.ac.id/handle/123456789/393?show=full.
} 


\section{Metode Penelitian}

Penelitian ini menggunakan pendekatan kuantitatif dengan metode survey - korelasional. Populasi penelitian ini adalah seluruh pimpinan dan pengerja gereja aliran Pentakosta yang ada di Jawa Timur. Adapun sampel penelitian sebanyak 160 Orang pemimpin jemaat. Teknik pengumpulan data dilakukan melalui kuesioner dengan jenis tertutup dalam kalimat pernyataan baik positif maupun negatif, dengan menggunakan Skala Perilaku, dengan pilihan jawaban Sangat Sesuai (SS), Sesuai (S), Kadang-kadang Sesuai (KS), Tidak Sesuai (TS), dan Sangat Tidak Sesuai (STS). Istrumen penelitian sebelum digunakan dalam pengumpulan data dilakukan uji coba kepada sampel penelitian dan dilakukan pengujian validitas dan reliabilitas.

Instrumen penelitian dikembangkan berdasarkan konstruk yang diukur dengan 30 item istrumen yang dalam pengujian validitas menggunakan validitas kontruk (Contruct Validity) dengan Analisis Faktor Eksploratori (Exploratory Factor Analysis). Dari hasil analisis factor diperoleh nilai KMO sebesar 0,613 $(>0,05)$ dan uji Bartlett's $0,000(<0,05)$ yang telah memenuhi syarat sehingga dapat dilakukan analisis faktor dalam pengembangan instrumen penelitian. $^{24}$ Dari hasil pengembangan instrument, terdapat 17 item yang valid dan dikelompok dalam 4 (empat) faktor yang meliputi: 1) Memiliki perencanaan dalam menyiapkan pemimpin baru bagi gereja; 2) Memberikan bimbingan dan melakukan pendelegasian tugas pelayanan; 3) Memiliki karakter Kristus dan menjadi teladan; 4) Suksesor berasal dari keluarga. Sedangkan hasil pengujian reliabilitas diperoleh koefisien sebesar 0,887 . Teknik analisis data yang digunakan dalam penelitian ini, yaitu melalui analisis korelasi sederhana, regresi sederhana ${ }^{25}$ dan dilanjutkan dengan classification regression tree. Analisis data dilakukan menggunakan IBM SPSS 26.

\section{Pembahasan}

Dari analisis data deskriptif dari 160 orang pimpinan dan pengerja gereja, diperoleh hasil sebagai berikut:

Tabel 1. Analisis Deskripsi Data Penelitian

\begin{tabular}{|c|c|c|c|}
\hline Variabel & $\mathrm{N}$ & Mean & Std. Deviation \\
\hline Suksesi Kepemimpinan & 160 & 4.0833 & .43860 \\
\hline $\begin{array}{l}\text { Memiliki perencanaan dalam menyiapkan } \\
\text { pemimpin baru bagi gereja }\end{array}$ & 160 & 3.9220 & .57340 \\
\hline $\begin{array}{l}\text { Memberikan bimbingan dan melakukan } \\
\text { pendelegasian tugas pelayanan }\end{array}$ & 160 & 3.9969 & .54728 \\
\hline Memiliki karakter Kristus dan menjadi teladan & 160 & 4.4594 & .45461 \\
\hline Mengutamakan suksesor berasal dari keluarga & 160 & 4.0375 & .64318 \\
\hline
\end{tabular}

${ }^{24}$ Imam Ghozali, Aplikasi Analisis Multivariate Dengan Program SPSS (Semarang: Badan Penerbit Univeristas Diponegoro, 2005), 257.

${ }^{25}$ Mikha Agus Widiyanto, Statistika Terapan. Konsep Dan Aplikasi Dalam Penelitian Bidang Pendidikan, Psikologi Dan Ilmu Sosial Lainnya (Jakarta: PT Elex Media Komputindo, 2013), 181, 211. 
Berdasarkan analisis data memberikan gambaran bahwa sebanyak 53 atau 33,13\% pemimpin gereja yang memiliki skor di bawag rata-rata untuk suksesi kepemimpinan dan sebanyak 107 atau 66,87\% pemimpin gereja yang memperoleh skor di atas rata-rata. Dengan demikian, para pemimpin gereja cenderung menunjukkan pada suksesi kepemimpinannya dalam melaksanakan dan mengembangkan pelayanan gereja. Sebanyak 48 orang atau 30\% pemimpin gereja yang memperoleh skor di bawah rata-rata dan sebanyak 112 orang atau $70 \%$ pemimpin gereja yang memperoleh skor di atas rata-rata yang menunjukkan bahwa banyak pemimpin gereja telah memiliki perencanaan dalam menyiapkan pemimpin baru bagi gerejanya. Sebanyak 40 orang atau $25 \%$ pemimpin gereja yang memperoleh skor di bawah rata-rata dan sebanyak 120 orang atau $75 \%$ pemimpin gereja yang memperoleh skor di atas rata-rata yang menunjukkan bahwa pemimpin gereja telah memberikan bimbingan dan melakukan pendelegasian tugas pelayanan kepada calon-calon pemimpin yang dipersiapkannya. Sebanyak 88 orang atau 55\% pemimpin gereja yang memperoleh skor di bawah rata-rata dan sebanyak 72 orang atau $45 \%$ pemimpin gereja yang memperoleh skor di atas rata-rata yang menunjukkan bahwa pemimpin gereja belum seluruhnya menunjukkan memiliki karakter Kristus dan menjadi teladan. Sebanyak 131 orang atau $81,87 \%$ pemimpin gereja yang memperoleh skor di bawah rata-rata dan sebanyak 19 orang atau 18,13\% pemimpin gereja yang memperoleh skor di atas rata-rata yang menunjukkan bahwa pemimpin gereja tidak seluruhnya mengutamakan suksesor berasal dari keluarga.

Hasil analisis dalam pengujian hipotesis di ringkasakan sebagai berikut sebagai berikut:

Tabel 2. Koefisien Korelasi antar Variabel

\begin{tabular}{lcccc}
\hline Hubungan antar Variabel & $\beta$ & $\mathrm{t}$ & $\mathrm{p}$ & Hasil \\
\hline $\begin{array}{l}\text { menyiapkan pemimpin baru bagi gereja } \\
\text {-> Suksesi Kepemimpinan }\end{array}$ & 0.947 & 37,028 & 0,000 & Signifikan \\
\hline $\begin{array}{l}\text { Memberikan bimbingan dan melakukan } \\
\text { pendelegasian tugas pelayanan - }\end{array}$ & 0.837 & 19,247 & 0,000 & Signifikan \\
$\begin{array}{l}\text { Suksesi Kepemimpinan } \\
\begin{array}{l}\text { Memiliki karakter Kristus dan menjadi } \\
\text { teladan - > Suksesi Kepemimpinan }\end{array}\end{array}$ & 0.714 & 12,825 & 0,000 & Signifikan \\
\hline $\begin{array}{l}\text { Mengutamakan suksesor berasal dari } \\
\text { keluarga - > Suksesi Kepemimpinan }\end{array}$ & 0.133 & 1,682 & 0.093 & $\begin{array}{c}\text { Tidak } \\
\text { Signifikan }\end{array}$ \\
\hline
\end{tabular}

Sumber: Olahan Data Penelitian dengan SPSS

Hasil analisis pada Tabel 2 menunjukkan bahwa faktor memiliki perencanaan dalam menyiapkan pemimpin baru bagi gereja memiliki koefisien korelasi dengan suksesi kepemimpinan yang lebih besar dibandingkan yang lainnya, yaitu sebesar 0,947. Sedangkan faktor Memberikan bimbingan dan melakukan pendelegasian tugas pelayanan dan memiliki karakter Kristus dan menjadi teladan masing-masing memberikan koefisien korelasi sebesar 0,837 dan 0,714 yang signifikan pada $\alpha=0,05$. Sedangkan faktor suksesi dari berasal dari keluarga sebesar 0,133 yang tidak signifikan. Dengan demikian faktor suksesi kepemimpinan bukan terletak pada suksesornya dari keluarga, namun pada perencanaan dalam mempersipakan pemimpin gereja di masa yang akan datang. Faktor perencanaan yang baik dalam menyiapkan pemimpin baru mampu memberikan kontribusi sebesar $89,6 \%\left(\mathrm{r}_{\mathrm{yx} 1}^{2}\right)$ 
terhadap suksesi kepemimpinan gereja-gereja aliran Pentakosta, sedangkan sisanya sebesar 10,4\% dipengaruhi oleh faktor lainnya.

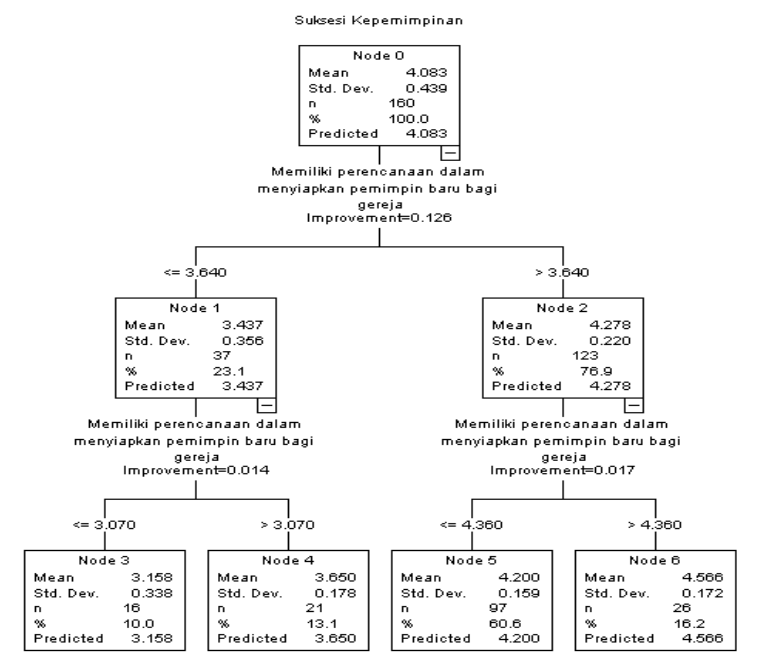

\section{Gambar 1. Hasil Analisis Clasification Regression Tree}

Berdasarkan hasil analisis Clasification Regression Tree pada gambar 1, bahwa memiliki perencanaan dalam menyiapkan pemimpin baru bagi gereja menjadi faktor yang paling dominan mempengaruhi suksesi kepemimpinan di era disruptif gereja-gereja aliran Pentakosta. Dari hasil analisis Clasification Regression Tree menunjukkan bahwa memiliki perencanaan dalam menyiapkan pemimpin baru mampu memprediksi dalam peningkatan suksesi kepemimpinan gereja-gereja aliran Pentakosta sebesar 15,70\%. Dengan demikian suksesi kepemimpinan gereja-gereja aliran Pentakosta sangat dipengaruhi kesiapan dan kesediaan pemimpin melalui perencanaan yang dalam jangka panjang dalam mengkader atau melakukan regenerasi pemimpin di masa yang akan datang. Pemimpin gereja harus mempersiapkan pemimpin yang akan datang bagi gerejanya dengan langkah-langkah yang signifikan. Pemimpin gereja apabila menyiapkan suksesornya dari keluarga, maka perlu dipersiyapkan secara terprogram. Secara khusus di era disruptif dengan mempersiyapkan dari aspek kompetensi dan penguasaan teknologi, serta karakter sesuai dengan tuntutan pelayanan gereja untuk menjadi seperti Kristus.

Hasil penelitian ini sejalan dengan hasil penelitian Lkama, Akinniyi dan Lkama bahwa perencanaan sebagai faktor yang penting dalam suksesi kepemimpinan. Perencanaan sebagai proses strategis dalam meminimalkan kesenjangan kepemimpinan yang memberikan peluang peningkatan keterampilan yang diperlukan bagi pemimin masa yang akan datang. ${ }^{26}$ Suksesi kepemimpinan memerlukan proses yang Panjang, dimana pemimpin harus mempersiapkan melalui perencanaan yang baik, mengikutsertakan dalam pelatihan guna melatih keterampilan dan kemampuannya.

Sejalan dengan Onyeukwu dan Jekelle bahwa dalam suksesi kepemimpinan mencakup keseluruhann kegiatan yang meliputi pra dan pasca dalam situasi kontrol. Untuk memastikan

${ }^{26}$ J. Drambi LKama, Ezekiel Oladejo Akinniyi, and Mary Julius Lkama, "Leadership Planning for Succession of Small and Medium Scale Enterprises for Entrepreneurs in Nigeria," ATBU, Journal of Science, Technology \& Education (JOSTE) 6, no. 1 (2018): 90-99. 
keberlanjutan kepemimpinan maka mengembangkan kemampuan dan pengetahuan ke depannya organisasi serta memberikan dorongan kepada individu suksesor. Dalam hal inilah diperlukan langkah-langkah dan prosedur perencanaan dalam suksesi kepemimpinan. ${ }^{27}$ Sejalan dengan hasil kajian McEntire dan Greene-Shortridge bahwa perencanaan dalam suksesi menjadi faktor penting dalam pengembangan organisasi melalui pengembangan talenta sumber daya yang ada. ${ }^{28}$ Suksesi kepemimpinan membutuhkan perencanaan yang tidak hanya pada proses pergeseran atau pemindahan kewenangan atau jabatan sebagai pemimpin. Namun pada proses pra, yang perlu memperhatikan aspek kemampuan dan pengetahuan dari suksesor serta motivasinya untuk pengembangan organisasi yang akan dilanjutkan kepemimpinannya. Ketika pergeseran kepemimpinan telah dilakukan juga perlu kontrol pemimpin untuk memastikan keberlanjutannya demi keberhasilan dan pengembangan organisasi tersebut.

Pada konteks Yosua ketika Musa telah melantiknya (Bil. 27:12-23), menunjukkan bahwa suksesi kepemimpinan karena Tuhan yang memilih dan Musa menetapkan jauh sebelum kematiannya (Bil. 27:15-23; Ul. 31:14-15, 23; 34:9). Yosua menjadi pemimpin bangsanya selama masa penaklukkan dan pembagian wilayah di Kanaan. Ia juga yang memimpin pembaharuan perjanjian dengan TUHAN di gunung Ebal dan Sikhem (Jo. 8:30-35; 24:128). ${ }^{29}$ Suksesi kepemimpinan Musa kepada Yosus selain faktor Tuhan yang menetapkan juga, faktor Musa merencanakan dan melakukan regenerasi yang tepat. Setelah Musa melantik Yosua, Musa masih berperan dan memegang kendali untuk memastikan keberlanjutan dalam kepemimpinan bagi bangsa Israel. Musa masih melakukan tugasnya sampai pada akhir hidupnya (Ul. 32:48-52). Demikian juga dalam suksesi kepemimpinan Yesus kepada para murid-Nya. Yesus melatih dan mempersipakan muri-murid yang kemudian melanjutkan tugas kepemimpiannNya (Mat. 4:18-19). Demikian juga Paulus mempersipakan Timotius, Titus dan anak didiknya yang lain, melalui proses yang panjang, meliputi masa pra dan pasca suksesi kepemimpinan. Masa pra menunjuk pada keterlibatan para murid baik rasul-rasul bersama-sama Yesus dan juga Paulus dengan para anak didiknya, dalam proses persiapan dan pengkaderan sampai pada pasca di mana adanya pendelegasian dan kepercayaan melaksanakan tugas penggembalaan (1Tim. 1:1-2; Tit. 1:4).

Suksesor dari anggota keluarga, tidak sekedar dilibatkan dalam pelayanan ketika pemimpin sudah mulai usia senja atau kemampuannya tidak optimal lagi, melainkan melatih dan meningkatkan kemampuannya pada bidang-bidang yang sesuai dengan pelayanan gereja di masa sekarang ini. Secara khusus dalam penguasaan teknologi. Tidak dapat dipungkiri bahwa di tengah-tengah situasi pendemi Covid-19 gereja diperhadapkan pilihan untuk menggunakan teknologi dalam pelaksanaan ibadah bahkan dalam berbagai kegiatan rapat gereja. Ketidakmungkinan mengumpulkan orang banyak menjadikan teknologi sebagai solusi. Gereja

${ }^{27}$ Pauline Onyeukwu and Helen E. Jekelle, "Leadership Succession and Sustainability of Small Family Owned Businesses in South East Nigeria," Open Journal of Business and Management 07, no. 03 (2019): 12071224, http://doi.ord/10.4236/ojbm.2019.73085.

${ }^{28}$ Lauren E. McEntire and Tiffany M. Greene-Shortridge, "Recruiting and Selecting Leaders for Innovation: How to Find the Right Leader," Advances in Developing Human Resources 13, no. 3 (2011): 266278, http://doi.org/10.1177/1523422311424712.

${ }_{29}$ Jonathan Octavianus, “Transisi Kepemimpinan Dalam Alkitab,” Kerusso 1, no. 1 (2016): 16-38. 
menggunakan media sosial seperti facebook, YouTube, zoom, google meet, live streaming dengan menggunakan berbagai aplikasi seperti OBS, Vimix, dan aplikasian lainnya yang semuanya memerlukan penguasaan teknologi. Surna dan Suseno dari hasil penelitiannya dalam penggunaan media komunikasi dalam ibadah, sebanyak 45,3\% menggunakan live streaming, sebanyak 17\% menggunakan zoom dan sebanyak 3,5\% menggunakan live streaming dan zoom. Sedangkan sebanyak 1,3\% masih melakukan tatap muka di gereja dan rumah dalam kelompok-kelompok kecil. ${ }^{30}$

Dengan demikian, gereja pada era disruptif, karena kondisi pandemi Covid-19 sudah beralih pada penggunaan teknologi, kemungkinan penggunaan berbagai media teknologi akan berlanjut. Dengan demikian, sejalan dengan hasil penelitian ini bahwa pemimpin gereja pada era disruptif tidak hanya membutuhkan kompetensi mengenai penguasaan bidang teologi saja, melainkan juga teknologi agar pelayanannya menjadi efektif. Pemimpin gereja masa sekarang agar sukses dalam mempersiapkan generasi selanjutnya sebagai pemimpin, secara khusus suksesornya dari anggota keluarga, maka kemampuannya harus dipersipakan melalui pelatihan, pendidikan dan pengembangan diri dengan mengikuti berbagai kegiatan peningkatan untuk penguasaan bidang teknologi. Peningkatan kompetensi ini yang dilakukan secara terperencana dengan baik dan berkesinambungan.

\section{Kesimpulan}

Berdasarkan hasil analisis disimpulkan bahwa perencanaan dalam mempersipakan pemimpin gereja yang akan datang menjadi faktor yang paling dominan menetukan suksesi kepemimpinan gereja-gereja aliran Pentakosta. Suksesi kepemimpinan gereja memerlukan waktu yang Panjang dalam mempersipakan pemimpin yang akan datang dalam pengembangan gereja. Suksesi kepemimpinan tidak semata-mata mempercayakan estafet kepemimpinan pada suksesor yang berasal dari keluarga. Dalam arti, tidak hanya sekadar mendelegasikan tugas kepemimpinan pada anggota keluarga tanpa memperhatikan dan mempersipakan melalui perencanaan yang baik. Suksesor yang berasal dari keluarga harus benarbenar dilatih, memiliki kemampuan, keterampilan, berkarakter Kristus dan mampu mengemban tugas kepemimpinan yang beroientasi pada pengembangan gereja yang mampu menjawab tantangan di era disruptif.

Suksesi kepemimpinan pada gereja-gereja aliran Pentakosta hendaknya mampu mengikuti pergeseran dan perkembangan secara khusus di era disruptif, yang menuntut kemampuan dan keterampilan dalam bidang teknologi informasi dan komunikasi. Bagi generasi milenial gereja, membutuhkan pemimpin yang memahami cara pikir, cara kerja dan potensi yang dimiliki, serta keteladanannya, sehingga pemimpin berikutnya mampu menggerakkan generasi milenial dalam pengembangan gereja yang dipimpinnya.

${ }^{30}$ Suriawan Surna and Aji Suseno, "Pandangan Teologis Live Streaming Atau Zoom Sebagai Sarana Ibadah Bersama Di Masa Pandemi Covid 19," Jurnal Teologi Praktika 1, no. 2 (2020): 137-152, http://doi.org/10.51465/jtp.v1i2.18. 


\section{Referensi}

Atmaja, Hanung Eka. "Suksesi Kepemimpinan Perusahaan Di Indonesia.” Jurnal Rekomen (Riset Ekonomi Manajemen) 1, no. 2 (2018): 45-56.

Bakar, Resekiani Mas, Benny Enrico Leonard Panggabean, and Eva Meizarra Puspita Dewi. "Tantangan Pendidikan Di Era Disruptif: Ujian Online Berbasis Smartphone Dengan Pengembangan Aplikasi XSIA.” Jurnal Psikologi Talenta 4, no. 1 (2018): 30-39. http://ejournal.uin-suska.ac.id/index.php/psikologi/article/view/165.

Chou, Shih Yung. "Millennials in the Workplace: A Conceptual Analysis of Millennials' Leadership and Followership Styles." International Journal of Human Resource Studies 2, no. 2 (2012): 71-83. http://doi.org/10.5296/ijhrs.v2i2.1568.

Ghozali, Imam. Aplikasi Analisis Multivariate Dengan Program SPSS. Semarang: Badan Penerbit Univeristas Diponegoro, 2005.

Hidayat, Moury Setiawan. "Studi Narasi Suksesi Kepemimpinan Musa Oleh Yosua, Dan Implikasinya Bagi Suksesi Kepemimpinan Rohani.” Sekolah Tinggi Teologi SAAT, 2015. http://repository.seabs.ac.id/handle/123456789/393?show=full.

Kamener, Dahliana, and Daniati Putri. "Analisis Keberhasilan Suksesi Perusahaan Keluarga Di Kota Padang." Industrial Research Workshop and National Seminar Politeknik (2017): 20-26.

Lim, Alex. "Integritas Spiritual Dan Kapabilitas Kepemimpinan Gereja Tionghoa." Veritas 11, no. 2 (2010): 207-229.

LKama, J. Drambi, Ezekiel Oladejo Akinniyi, and Mary Julius Lkama. "Leadership Planning for Succession of Small and Medium Scale Enterprises for Entrepreneurs in Nigeria." ATBU, Journal of Science, Technology \& Education (JOSTE) 6, no. 1 (2018): 90-99.

McEntire, Lauren E., and Tiffany M. Greene-Shortridge. "Recruiting and Selecting Leaders for Innovation: How to Find the Right Leader." Advances in Developing Human Resources 13, no. 3 (2011): 266-278. http://doi.org/10.1177/1523422311424712.

Nugroho, Gregoruis Kukuh. "Educational Leadership In Disruptive Era: A Faith Challenge Facing Indonesia.” JPAK: Jurnal Pendidikan Agama Khatolik 19, no. 2 (2019): 91100. https://doi.org/10.34150/jpak.v19i2.243.

Objantoro, Enggar. "Religious Pluralisme and Christian Responses." Evangelikal: Jurnal Teologi Injili dan Pembinaan Warga Gereja 2, no. 1 (2018): 1-9. https://doi.org/10.46445/ejti.v2i1.94.

Octavianus, Jonathan. “Transisi Kepemimpinan Dalam Alkitab.” Kerusso 1, no. 1 (2016): 1638.

Onyeukwu, Pauline, and Helen E. Jekelle. "Leadership Succession and Sustainability of Small Family Owned Businesses in South East Nigeria." Open Journal of Business and Management 07, no. 03 (2019): 1207-1224. http://doi.ord/10.4236/ojbm.2019.73085.

Putriastuti, Bernadeta Cahya Kumala, and Alessandro Stasi. "How to Lead the Millennials: A Review of 5 Major Leadership Theory Groups." Journal of Leadership In Organizations 1, no. 2 (2019): 96-111. https://doi.org/10.22146/jlo.46562.

Pyöriä, Pasi, Satu Ojala, Tiina Saari, and Katri-Maria Järvinen. "The Millennial Generation: A New Breed of Labour?" SAGE Open 7, no. 1 (2017): 1-14. http://doi.org/10.1177/2158244017697158.

Remiasa, Marcus, and Shelvy Anggraini Wijaya. “Analisis Proses Suksesi Perusahaan Keluarga Studi Pada Pt Puterasean.” Kinerja 18, no. 2 (2014): 141-156.

Ronda, Daniel. "Kepemimpinan Kristen Di Era Disrupsi Teknologi." Evangelikal: Jurnal Teologi Injili dan Pembinaan Warga Jemaat 3, no. 1 (2019): 1. http://doi.org/10.46445/ejti.v3i1.125. 
Salleh, Lailawati Mohd., and Muhammad Fadhi Abdul Rahman. "A Comparative Study of Leadership Succession Models.” Science International 29, no. 4 (2017): 791-796. https://lib.pepperdine.edu/login?url.

Selesho, Jacob M. "The Role of Leadership in Organisational Regeneration: Incident of School Improvement." Mediterranean Journal of Social Sciences 5, no. 7 (2014): 317323.

Shergold, Peter. "Regeneration: New Structures, New Leaders, New Traditions." Australian Journal of Public Administration 64, no. 2 (2005): 3-6. http://doi.org/10.1111/j.14678500.2005.00428.x.

Siahaya, Johannis. “Kepmimpinan Kristen.” Teruna Bhakti 1, no. 1 (2018): 1-16. http://ejournal.stakterunabhakti.ac.id/index.php/teruna/issue/archive.

Surna, Suriawan, and Aji Suseno. "Pandangan Teologis Live Streaming Atau Zoom Sebagai Sarana Ibadah Bersama Di Masa Pandemi Covid 19." Jurnal Teologi Praktika 1, no. 2 (2020): 137-152. http://doi.org/10.51465/jtp.v1i2.18.

Wanggi, Amelia, Mutiara Panggabean, and Tiara Puspa. "Pengaruh Succession Planning, Transformational Leadership, Training Satisfaction Terhadap Turnover Intention Karyawan Pada Sektor Publik Kementerian Agama Jakarta Pusat.” Esensi: Jurnal Bisnis dan Manajemen 9, no. 1 (2019): 79-90. http://doi.org/10.15408/ess.v9i1.12491.

Wasono, Leonardus W., and Asnan Furinto. "The Effect of Digital Leadership and Innovation Management for Incumbent Telecommunication Company in the Digital Disruptive Era." International Journal of Engineering and Technology(UAE) 7, no. 2 (2018): 125130.

Widiyanto, Mikha Agus. Statistika Terapan. Konsep Dan Aplikasi Dalam Penelitian Bidang Pendidikan, Psikologi Dan Ilmu Sosial Lainnya. Jakarta: PT Elex Media Komputindo, 2013.

Widyawulandari, Rizki, Sarwanto Sarwanto, and Mintasihu Indriayu. "The Use of Interactive Multimedia in Learning Based on Disruption Era At Elementary School." Social, Humanities, and Educational Studies (SHEs): Conference Series 1, no. 1 (2018): 697704.

Wijaya, Yahya. "Kepemimpinan Yesus Sebagai Acuan Bagi Kepemimpinan Gereja Masa Kini.” Jurnal Jaffray 16, no. 2 (2018): 129. http://doi.org/10.25278/jj71.v16i2.287.

“Trik Menjadi Pemimpin Di Era Disruptif," n.d. https://ofiskita.com/articles/detail/trikmenjadi-pemimpin-di-era-disruptif. 